\title{
Fault detection using neural network
}

\author{
Elistia Liza Namigo \\ Physics Department of Andalas University \\ Kampus Limau Manis Padang Sumatera Barat \\ Email : elistializanamigo@fmipa.unand.ac.id
}

Received 22 October 2016, Revised 27 November 2016, Accepted 6 January 2017

\begin{abstract}
Fault detection technique using neural networks have been successfully applied to a seismic data volume. This technique is basically creating a volume that highlights faults by combining the information from several fault indicators attributes (i.e. similarity, curvature and energy) into fault occurrence probability. This is performed by training a neural network on two sets of attributes extracted at sample locations picked manually one set represents the fault class and the other represents the non-fault class. The next step is to apply the trained artificial neural network on the seismic data. Result indicates that faults are more highlighted and have better continuity since the surrounding noise are mostly suppressed.
\end{abstract}

Keywords: fault detection; multi-attribute analysis; neural networks; fault cube.

\section{Introduction}

Fault detection plays an important role in the field of seismic interpretation since knowledge of faults location leads to a better understanding in geological system in the mission to locate potential area for hydrocarbon exploration. Conventionally, faults are detected through manual picking on a seismic section by trained and experienced seismic interpreters. Picking is performed by identifying anomalies such as discontinuities or grooves in the seismic reflectors. This technique works best for large/coarse faults. For finer faults with the size much smaller than the resolution limit of seismic surveys, this technique is extremely challenging and very time consuming especially to untrained eyes.

In the last few decades a novel fault detection technique is developed by utilizing seismic attributes as tools to identify fault locations as in Luo et. al. (1995), Song et. al. (2012) and Odoh et. al. (2014). According to Mehdal et. al. (1999), the technique gives better results on object detection. The process is less time-consuming while minimizing subjectivity since it requires no special skills as in conventional faultpicking.

Seismic object is an entity which is characterized by different seismic response compared to the response in the surrounding area. The difference in response is indicated significantly by seismic attributes. Seismic attribute is defined as quantity extracted or derived from seismic data. This quantity can further be analyzed to 
enhance information from a traditional seismic image in order to obtain better geological or geophysical interpretation of the data. Since there is no single attribute is particularly sensitive to a particular geological object on seismic data (in this case fault), several seismic attributes should be used simultaneously for fault detection. Some among attributes used as fault indicators are dip, curvature, similarity, coherence and energy (Daber et al, 2010).

A technique was developed to combine multiple attributes into a single attribute that is sensitive to seismic objects contained in the geological seismic data (Zheng et al, 2014). The technique is an iterative process that combines seismic attribute, neural networks (NN) and image processing. Figure 1 shows an example detect the presence of gas chimney solely from seismic data only.

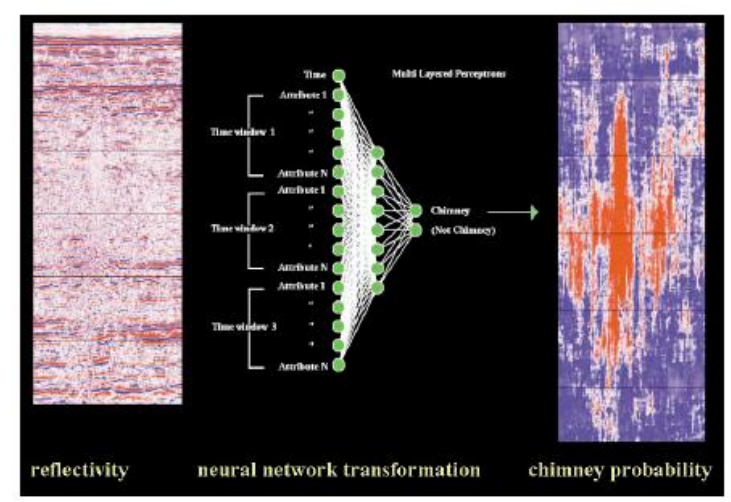

Figure 1. Conversion process of seismic data into chimney occurence probability. The NN uses 16 seismic attributes to classify each class of data points into "chimney" or "non-chimney". Only the value for 'chimney' node is passed to produce the output cube. Warm (red) color indicates high chimney probabillity. (Meldahl et.al., 1999).

The process starts with selecting attributes and determining the extraction windows for object detection. This is performed by training a neural network (NN) to identify the object that has previously been introduced to 'seed'. The NN will then transform all the attributes to a single new attribute that indicates the probability of the object at a certain position on the seismic section. Occurrence probability of an object (in this case gas chimney) is displayed in a cube. This can be optimized with image processing techniques and iteration process.

\section{Methods}

In this study, NN fault detection technique is applied on a sample seismic data volume from a field off shore Texas using Opendtect software. Attributes used are similarity, curvature, and energy. The workflow of the technique is as follows

1) Scanning the data to identify part of the seismic section where faults are apparent.

2) Creating two pickset for pattern recognition: one for 'fault' and another for 'nonfault' 
3) Choosing few examples for 'fault' and 'non-fault' part of the chosen seismic section in step 1.

4) Selecting the attribute (in this study used similarity, curvature, and energy.

5) Training the $\mathrm{NN}$ with the attributes and picksets as input..

6) Applying the trained NN on seismic data so that fault probability cube is generated.

\section{Results and Discussion}

Figure 2 shows initial seismic section before the fault detection method is applied. From the picture it can be seen that faults are not clearly defined, this might be due to seismic noises and poor seismic resolution.

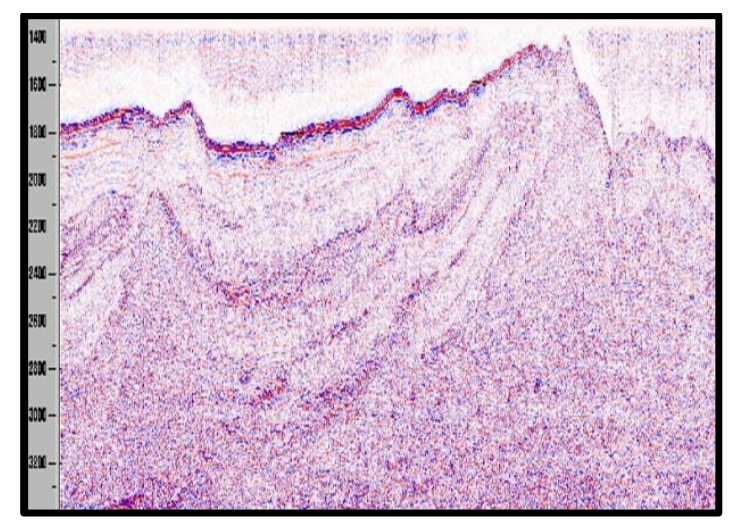

Figure 2. Initial seismic section before applying NN for fault detection.

The first step of the process is to create picksets 'fault' and 'non-fault' by picking at points identified as faults and non-fault. Picking is done on a part of seismic section where faults are clearly visible visually. Picking for pickset 'fault' is done in several different faults as much as 300 times. Similarly, picking is also carried out on the nonfault area of the same part of seismic section. Picking is conducted in the area of high energy and low energy region. Picking for non-fault pickset is also performed on nonfaultes areas with apparent noises.These two picksets with attributes (similarity, curvature and energy) are used as input for NN training. For output, option 'Fault-Yes' is selected which means that only the value for the "fault" node is passed to produce the output cube.

Figure 4 shows fault probability that describes the presence of a fault on a certain position on the seismic section of Figure 1. This is obtained after 17 iterations. The red color indicates a high probability of fault occurrence. 


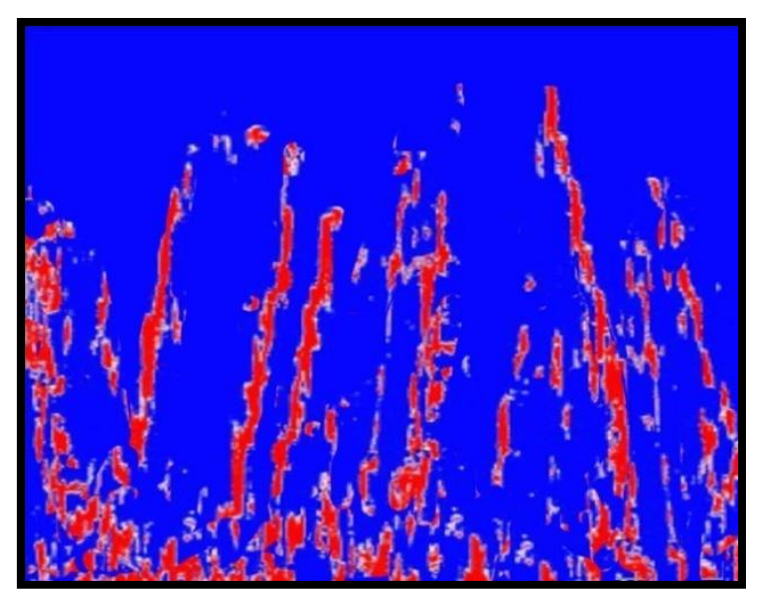

Figure 3. Fault occurrence probability.

The fault occurrence probability generated, as shown in Figure 4 is then applied to the seismic section in Figure 2. The result is as shown in Figure 4. The new seismic section shows significant improvement in terms of signal to noise ratio and better continuity. Faults are clearly defined in the seismic section.

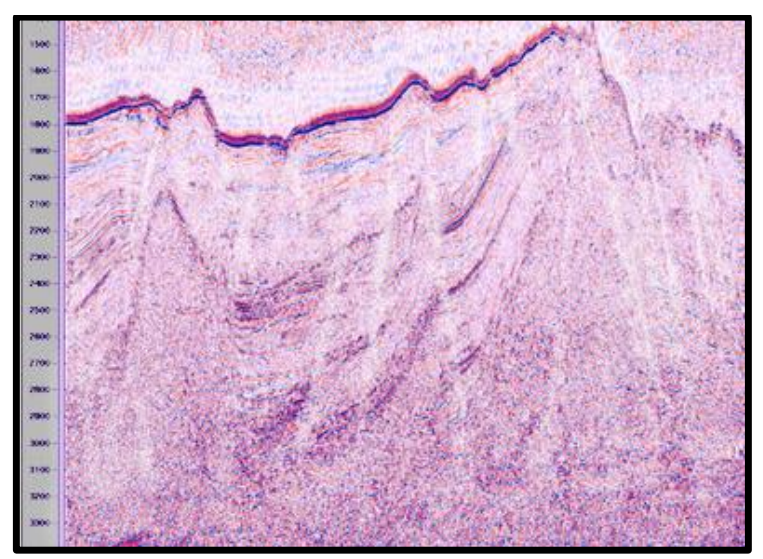

Figure 4. Seismic section after application of the trained NN.

\section{Conclusion}

Combination of multi-attribute analysis and artificial neural networks have been successfully applied for fault detection. The success of the fault detection relies heavily on the selection of appropriate attributes as fault indicators, the number of attributes that are used, the number of picking on the process creating the picksets (pickset 'fault' and 'non-fault') and number of iterations. In this study, by using three attributes ; similarity,curvature- faults can be detected and noise is significantly reduced.

\section{References}

Daber, R., A.Aqrawi, Schlumberger Limited. (2010). Petrel 2010: Interpreters Guide to Seismic Attributes.

Luo Y., W.G. Higgs, W.S.Kowalik (1995), Edge Detection and Stratigraphic Analysis Using 3D Seismic Data. SEG Expanded Abstract, 5. 
Meldhal dkk. (1999). Survey Evaluation and Design: Prediction of Resolution Versus Line Interva. SEG 1999 Expanded Abstracts.

Odoh, B.I., Juliet Nneamaka Ilechukwu, Nnaemeka Ifeanyi Okoli. (2014). The Use of Seismic Attributes to Enhance Fault Interpretation of $\mathrm{O}^{\mathrm{T}}$ Field, Niger Delta. International Journal of Geosciences, 5, 826-834

Song, Jianguo, Xing Mu, Zhe Li, Changjiang Wang, Yongzhuang Sun. (2012). A Faults Identification Method Using Dip Guided Facet Model Edge Detector. SEG Technical Program Expanded Abstract. 1-5.

Zheng, Z.H., P. Kavousi, H. B. Di, (2014). Multi-Attributes and Neural Network-Based Fault Detection in 3D Seismic Interpretation", Advanced Materials Research, Vol. 838-841, 1497-1502. 